\title{
The Copernicus CO2M mission for monitoring anthropogenic carbon dioxide emissions from space
}

Bernd Sierk, Valerie Fernandez, J.-L. Bézy, Y. Meijer, Y. Durand, et al.

Bernd Sierk, Valerie Fernandez, J.-L. Bézy, Y. Meijer, Y. Durand, G. Bazalgette Courrèges-Lacoste, C. Pachot, A. Löscher, H. Nett, K. Minoglou, L. Boucher, R. Windpassinger, A. Pasquet, D. Serre, F. te Hennepe, "The Copernicus $\mathrm{CO} 2 \mathrm{M}$ mission for monitoring anthropogenic carbon dioxide emissions from space," Proc. SPIE 11852, International Conference on Space Optics - ICSO 2020, 118523M (11 June 2021); doi: 10.1117/12.2599613

SPIE Event: International Conference on Space Optics - ICSO 2021, 2021, Online Only 


\section{International Conference on Space Optics-ICSO 2020}

Virtual Conference

30 March-2 April 2021

Edited by Bruno Cugny, Zoran Sodnik, and Nikos Karafolas
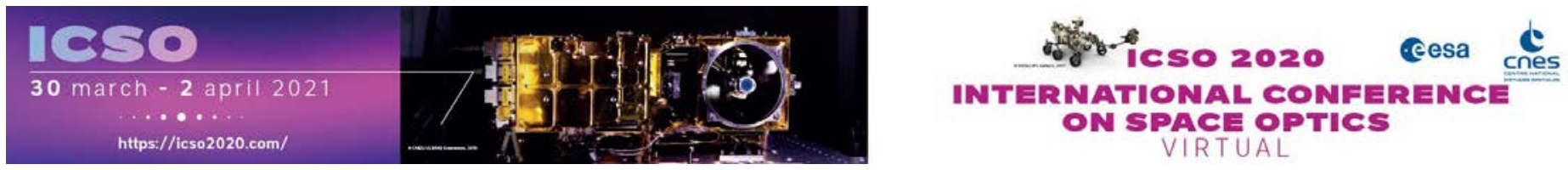

\section{The Copernicus CO2M mission for monitoring anthropogenic carbon dioxide emissions from space}

\section{Cesa issopoceatings lecnes}




\title{
The Copernicus CO2M mission for monitoring anthropogenic carbon dioxide emissions from space
}

\author{
B. Sierk ${ }^{\mathrm{a}}$, V. Fernandez ${ }^{\mathrm{a}}$, J.-L. Bézy ${ }^{\mathrm{a}}$, Y. Meijer ${ }^{\mathrm{b}}$, Y. Durand ${ }^{\mathrm{a}}$, G. Bazalgette \\ Courrèges-Lacoste $^{\mathrm{a}}$, C. Pachot ${ }^{\mathrm{a}}$, A. Löscher ${ }^{\mathrm{a}}, \mathrm{H}$. Nett $^{\mathrm{a}}$, K. Minoglou ${ }^{\mathrm{a}}$, L. Boucher $^{\mathrm{b}}$, R. \\ Windpassinger $^{\mathrm{a}}$, A. Pasquet ${ }^{\mathrm{a}}$, D. Serre ${ }^{\mathrm{c}}$, and F. te Hennepe ${ }^{\mathrm{d}}$ \\ aEuropean Space Agency, Keplerlaan 1, 2200 AG Noordwijk ZH, The Netherlands \\ ${ }^{b}$ RHEA for the European Space Agency, Keplerlaan 1, 2200 AG Noordwijk ZH, The \\ Netherlands

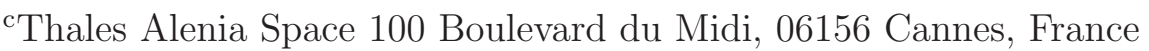 \\ ${ }^{d}$ OHB System, Manfred-Fuchs-Platz 2-4, 28359 Bremen, Germany
}

\begin{abstract}
The European Space Agency (ESA), in collaboration with the European Commission (EC) and EUMETSAT, is developing a space-borne observing system for quantification of anthropogenic carbon dioxide $\left(\mathrm{CO}_{2}\right)$ emissions. Forming part of the EC's Copernicus programme, the $\mathrm{CO}_{2}$ monitoring $(\mathrm{CO} 2 \mathrm{M})$ mission will be implemented as a constellation of identical satellites, to be operated over a period of at least 7 years and measuring $\mathrm{CO}_{2}$ concentration in terms of column-averaged mole fraction (denoted as $\mathrm{XCO}_{2}$ ). Each satellite will continuously image $\mathrm{XCO}_{2}$ along the satellite track on the sun-illuminated part of the orbit, with a swath width of $>250$ $\mathrm{km}$. Observations will be provided at a spatial resolution of $2 \times 2 \mathrm{~km}^{2}$, with high precision $(<0.7 \mathrm{ppm})$ and accuracy (bias $<0.5 \mathrm{ppm}$ ). To this end, the payload comprises a suite of instruments addressing the various aspects of the challenging observation requirements: A push-broom imaging spectrometer will perform co-located measurements of top-of-atmosphere radiances in the Near Infrared (NIR) and Short-Wave Infrared (SWIR) at high to moderate spectral resolution (NIR: 747-773nm@0.1nm, SWIR-1: 1595-1675nm@0.3nm, SWIR-2: 1990$2095 \mathrm{~nm} @ 0.35 \mathrm{~nm})$. These observations are complemented by measurements in the visible spectral range (405-490 $\mathrm{nm} @ 0.6 \mathrm{~nm})$, providing vertical column measurements of nitrogen dioxide $\left(\mathrm{NO}_{2}\right)$ that serve as a tracer to assist the detection of fossil-fuel emission plumes (e.g. from coal-fired power plants and cities). High quality retrievals of carbon dioxide concentration will be ensured even over polluted industrial regions, thanks to co-located measurements of aerosols performed by a Multi-Angle Polarimeter (MAP). Finally, measurements of a threeband Cloud Imager, co-registered with the $\mathrm{CO}_{2}$ observations, will provide the required cloud-flagging capacity at sub-sample level $(<200 \mathrm{~m}$ resolution). This paper will review the results of the Phase A/B1 instrument studies carried out in 2018-2019, including technology pre-development activities, and highlight the identified engineering challenges. The preliminary design of the CO2M mission's instruments at the beginning of the implementation phase will be presented, along with an outlook on the development activities under the Phase B2CD programme.
\end{abstract}

Keywords: Copernicus programme, imaging spectrometers, carbon dioxide, greenhouse gas emissions

\section{INTRODUCTION}

The 2015 United Nations Climate Change Conference (COP 21) culminated in the establishment of the Paris Agreement, which established the goal of significantly reducing anthropogenic emissions of greenhouse gases [1]. International treaties and agreements, aiming at reducing emission from fossil fuel combustion have been signed by many nations. While the targeted emission reductions are based on voluntary Nationally Determined Contributions (NDCs), there is a future demand for actionable information on the effectiveness of implemented measures and regulations. In this context, the European Commission has formulated a system architecture with

Further author information: (Send correspondence to B. S.)

E-mail: bernd.sierk@esa.int, Telephone: +31 715653919 
Monitoring and Verification Support capacity [2]. An earlier report identified the need of a multi-component observation system for quantification and monitoring of anthropogenic greenhouse gas emissions, involving in-situ and remote sensing observations on various spatial domains [3]. Besides on-ground measurements, one of the key components of the observing system will be space-borne observations of the most important anthropogenic greenhouse gases, carbon dioxide $\left(\mathrm{CO}_{2}\right)$ and methane $\left(\mathrm{CH}_{4}\right)$. The high-level observation requirements call for a multi-satellite constellation with imaging capability at high spatial resolution, global coverage and frequent re-visit. Spaceborne measurements of greenhouse gas concentrations were pioneered by the SCIAMACHY instrument on board ESA's Envisat satellite [4]. After the launch failure of NASA's Orbiting Carbon Observatory (OCO [5]) in 2009, JAXA's GOSAT satellite (nicknamed Ibuki) became the first dedicated mission to target $\mathrm{CO}_{2}$ and $\mathrm{CH}_{4}$ measurements from space [6]. GOSAT performs measurements of top-of-atmosphere (TOA) spectral radiance by means of a Fourier Transform Infrared Spectrometer (FTIR), with relatively large field-of-view (10.5 $\mathrm{km})$ and sampling distance between single soundings $(88 \mathrm{~km})$. In August 2014 NASA successfully launched OCO-2 $[7,8]$, which has since been providing continuous soundings of $\mathrm{XCO}_{2}$ at high spatial resolution $(\sim 3$ $\mathrm{km}^{2}$ ). The OCO-2 instrument is a three-band grating spectrometer operated in push-broom mode. Despite of its narrow swath width $(\sim 20 \mathrm{~km})$ and incomplete global coverage, OCO-2 has detected sources and sinks on regional scales over the globe [9], and even demonstrated the capability of imaging point sources, such as power plants [10]. In December 2016, the Chinese TanSat mission was launched [11], which has similar spatial resolution and coverage, and first results have been published [12]. In October 2018 JAXA launched GOSAT-2 [13], an FTIR offering improved accuracy and spatial sampling with respect to its predecessor [14]. In May 2019 NASA installed OCO-3 [15] on the International Space Station (ISS), a flight spare spectrometer of OCO-2 modified to facilitate observations of selected targets from the nadir-oriented ISS platform. First results confirm the feasibility of $\mathrm{CO}_{2}$ point-source detection from space [16]. At the time of writing this paper, there are several missions under preparation, most notably MicroCarb (led by CNES) [17] and the geostationary GeoCarb (University of Oklahoma) [18], which also feature high spatial resolution modes for point-source observation. Based on the results of on-going missions and previous instrument studies, there is now considerable heritage of space-borne greenhouse gas observations to design a system dedicated to anthropogenic $\mathrm{CO}_{2}$ monitoring.

The capability of point-source detection and quantification was a key feature of the CarbonSat mission [19], which was a candidate for ESA's Earth-Explorer programme in 2015. The mission concept combined a wide swath $(\sim 200 \mathrm{~km})$ with continuous, dense spatial sampling $(2 \mathrm{~km} \times 3 \mathrm{~km})$, allowing for imaging of emission plumes from power plants. Although CarbonSat was not selected for implementation, ESA further developed and extended the mission concept into a satellite constellation for broad coverage and a multi-instrument configuration for enhanced precision and accuracy. In 2018 and 2019, the European Space Agency (ESA) carried out technical feasibility (Phase-A/B1) studies for such an observing system with two industrial consortia led by Airbus Defense and Space and OHB, respectively. The studies were part of a series of Phase-A/B1 studies aiming at extending the capabilities of the Copernicus programme. In this frame, the $\mathrm{CO}_{2}$ monitoring $(\mathrm{CO} 2 \mathrm{M})$ mission is planned as a future Sentinel mission with a targeted launch date in 2025. The industrial activities were supported by scientific studies with the objective of identifying the observation requirements for a constellation of satellites equipped with a suite of instruments optimized for anthropogenic CO2 monitoring [20]. In November 2019 ESA released an ITT for the preparation of six high-priority Copernicus missions, and in April 2020 selected an industrial consortium led by OHB to implement the CO2M mission

This paper presents the mission architecture with a focus on the optical design of the instruments, with the main emphasis on the $\mathrm{CO}_{2}$ and $\mathrm{NO}_{2}$ imaging spectrometers (referred to as CO2I and NO2I, respectively). The driving mission and observation requirements are reviewed and their translation into instrument architecture and design is presented. Finally, the critical technologies are identified and the results of the pre-development activities reviewed.

\section{MISSION CONCEPT}

The overarching objective of the CO2M observing system is to provide actionable information for policy makers by means of accurate quantification of anthropogenic greenhouse gas emissions at various spatial scales (from the regional to country domain). This calls for highly accurate global mapping of carbon dioxide and methane concentration at sufficiently high spatial resolution and revisit frequency. The concentration of these two key 
greenhouse gases is measured in terms of their column-averaged dry air mole fractions, denoted as $\mathrm{XCO}_{2}$ and $\mathrm{XCH}_{4}$, respectively. Although $\mathrm{CH}_{4}$ is a more potent greenhouse gas than $\mathrm{CO}_{2}$, the latter is about 200 times more abundant and therefore results in larger radiative forcing. $\mathrm{CO}_{2}$ also drives the mission requirements as a well-mixed natural constituent of the atmosphere with relatively small regional variation, the largest part of which is caused by biogenic, natural sources and sinks. Significantly elevated values for $\mathrm{XCO}_{2}$ in excess of a few percent of the background value can be detected within down-wind plumes of coal-fired power plants, and potentially large cities. Since the $\mathrm{CO}_{2}$ quickly dilutes after emission, the expected signal of enhanced $\mathrm{XCO}_{2}$ depends on the size of the observed spatial samples (spatial resolution) and the wind speed. This drives the observation requirements of the space segment regarding retrieval precision and accuracy, as well as spatial sampling, resolution and global coverage. In particular high single-sounding precision is essential for identifying plumes of elevated $\mathrm{CO}_{2}$ concentration from instantaneous image acquisitions without regional and temporal averaging. This translates into stringent requirements for Signal-to-noise ratio (SNR), as well as spatial coregistration and spectral stability, which drive the instrument design. The derivation of radiometric and spectral sizing requirements for the CO2M mission is reported in [22]

Requirements for a space-borne component of an operational monitoring system have been identified in an expert study funded by the European Commission [3]. According to the report, monitoring of anthropogenic carbon emissions require a satellite constellation, observing $\mathrm{XCO}_{2}$ at high precision $(<0.7 \mathrm{ppm})$ and low systematic bias $(<0.5 \mathrm{ppm})$ with global coverage every 2-3 days. ESA has initiated scientific support studies to further consolidate observational requirements with particular emphasis on the precision (repeatability) and accuracy (systematic bias) of the $\mathrm{XCO}_{2}$ observations. The precision is mainly determined by the signal-to-noise ratio (SNR) of the measured TOA spectral radiance, as well as pseudo-noise from spatial co-registration and radiometric scene non- uniformity. Systematic biases may be introduced by instrumental errors like straylight, polarization sensitivity and detection non-linearity, as well as by geophysical effects, like the uncertainties in the aerosol distribution above the scene. The science studies carried out during Phase A/B1 resulted in recommendations regarding retrieval precision and accuracy, as well as spatial sampling and resolution and global coverage. These recommendations have been translated into a mission concept based on a constellation of identical satellites in sun-synchronous orbit (altitude $735 \mathrm{~km}$, LTDN 11:30). Their nadir pointing Field-of-Views (FoV) will be aligned such as to maximise the combined swath width and coverage. Each satellite will carry four instruments:

- The $\mathrm{CO}_{2}$ imager (CO2I), consisting of three spatially co-registered push-broom imaging spectrometers, measuring spectral radiance and solar irradiance in the NIR (747-773 nm), SWIR-1 (1595-1675 nm) and SWIR-2 (1990-2095 nm) at moderate spectral resolving power $(\mathrm{R}=5000-7000)$

- The $\mathrm{NO}_{2}$ imager (NO2I), operating in the visible spectral range (405-490 nm) and implemented as a fourth spectral band to the CO2I instrument

- The multi-angle polarimeter (MAP), a compact spectral imager with 40 field of views spanning a range of $+/-60^{\circ}$ of observation zenith angle (OZA) in along-track direction

- The three-band high spatial resolution cloud imager (CLIM)

In the following sections we will provide an overview over the above payload components.

\section{PAYLOAD COMPONENTS}

\subsection{The combined Carbon Dioxide and Nitrogen Dioxide Imager (CO2I and NO2I)}

Carbon dioxide concentration in terms of column-averaged mole fraction $\left(\mathrm{XCO}_{2}\right)$ is retrieved from measurements in three spectral bands in the near- and shortwave infrared regions (denoted as NIR and SWIR, respectively). Its quantitative measurement is a challenge due to the fact that $\mathrm{CO}_{2}$ is a natural and well-mixed constituent of Earth's atmosphere, and that enhanced concentrations from industrial and urban emissions are on the order of only a few percent of the background concentration. On the other hand, such emission sources are frequently accompanied by co-emitted nitrogen dioxide $\left(\mathrm{NO}_{2}\right)$, a trace gas for which there is considerable heritage of 
measurements from space, e.g. 21. $\mathrm{NO}_{2}$ absorbs in the visible spectrum (VIS), where typically higher signal-tonoise ratios can be achieved than in the NIR and SWIR. $\mathrm{NO}_{2}$ enhancements can therefore be used as a tracer for $\mathrm{CO}_{2}$ emission. This is demonstrated in Fig. 1, which is showing simulated maps of $\mathrm{XCO}_{2}$ (left) and $\mathrm{NO}_{2}$ column (right) over an industrial area with emission sources, assuming CO2M resolution and precision requirements. Emission plumes for both molecular species are clearly visible and correlated.

In the frame of scientific support analyses it has been shown, that simultaneous and co-located measurements of $\mathrm{NO}_{2}$ column density greatly enhance the capability of detecting the location of $\mathrm{CO}_{2}$ plumes [20]. For this reason, the CO2M mission will embark a single-band (VIS) $\mathrm{NO}_{2}$ imager (NO2I) for simultaneous and co-located measurements with the three-band $\mathrm{CO}_{2}$ imager (CO2I). While the requirements would allow for two separate instruments, the selected concept for CO2M implements a combined four-band instrument, which will be referred to as CO2I/NO2I. The following sections will address the main components of the combined CO2I/NO2I instrument.
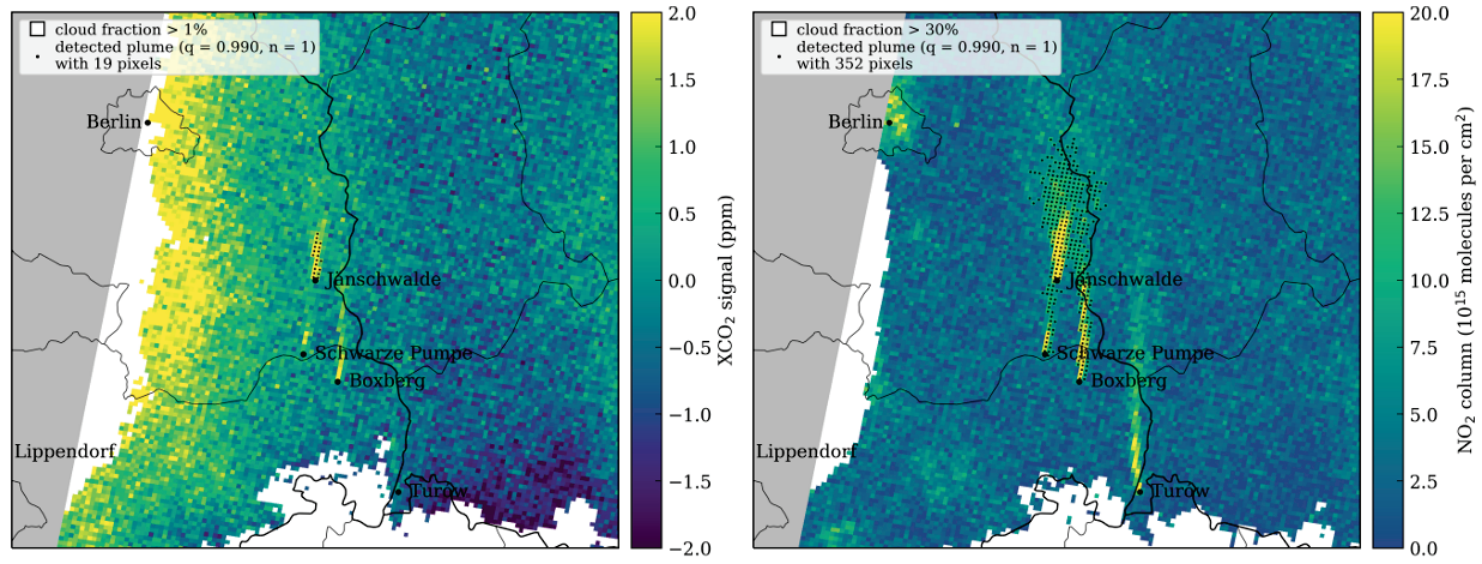

Figure 1. Simulated imaging performance of the observing system for $\mathrm{XCO}_{2}$ (left) and $\mathrm{NO}_{2}$ vertical column (right). The image captures four point sources, including Europe's third-largest lignite-fired power-plant in Jaenschwalde, Germany. The emission plumes are clearly visible against the background values and correlated between the two molecular species. The $\mathrm{NO}_{2}$ retrievals are less noisy, which can be exploited for better flux estimation in synergistic analysis (courtesy of EMPA).

\subsubsection{Observation Principle}

The first component of the instrument suite is the carbon dioxide imager, which is a push-broom imaging spectrometer featuring three spatially-collocated spectral bands in the near- and shortwave infrared regions (NIR and SWIR, respectively). The measurement principle of a push-broom imaging spectrometer is illustrated in Fig. 2. A telescope images the ground scene on the entrance slit of the spectrometer. The projected slit length in across-track (ACT) direction defines the swath width of the instrument and consequently its spatial coverage. As the spacecraft moves along its orbit, the projected slit continuously scans the Earth surface in along-track (ALT) direction. During this motion the diffraction gratings spectrally disperse the slit image perpendicular to the ACT direction and the spectrometer cameras focus the two-dimensional images onto the array detectors. The distance travelled during dwell time (exposure time between two successive read-outs) provides the spatial sampling in ALT direction during acquisition. At any instant, the detector pixels sample the image spatially in ACT and spectrally in ALT direction.

With this technique, the CO2I measures the up-welling top-of-atmosphere spectral radiance in nadir viewing geometry at moderate spectral resolution and wide bandwidth, compared to the heritage OCO-2 and the upcoming MicroCarb missions. The instrument is also characterised by a high signal-to-noise ratio even for low radiance levels. This is crucial in order to radiometrically resolve the small differences in absorption signature from emission-enhanced $\mathrm{XCO}_{2}$ typical for point sources, in particular in mid- and high latitudes. The optimisation of spectral resolution requirements for CO2M is reported in [23]. The resulting specifications for the 




Figure 2. Principle of a push-broom imaging spectrometer. The entrance slit of the spectrometer is imaged onto the Earth surface, defining the swath width in across-track (ACT) direction. The instrument spectrally disperses the slit image in along-track (ALT) direction. Spatially the image is sampled by the detector pixels in ACT direction and by the spacecraft motion during integration time in ALT direction.

NIR and two SWIR bands are summarised in Fig 3, which also depicts simulated radiance spectra for the three spectral bands, and their structure explained in the caption.

The three spectral bands are measured by individual spectrometers, but share a common front optics (telescope), entrance slit, calibration unit and collimator. This is imposed by the critical requirement of spatial co-registration, which is significantly more stringent than for atmospheric chemistry missions like e.g. Sentinel-4 and -5 . However, the CO2I instrument operates according to the same observation principle and similar spectral range, which is why they can be considered as heritage missions:

\subsubsection{CO2I and NO2I design}

The requirements and observation principle have been translated into an optical design by the payload prime Thales-Alenia in France (TAS-F). The concept foresees three mirror anastigmat (TMA) type of telescope featuring a Babinet pseudo-depolariser polarisation scrambler as the first optical element, which reduces degree of polarization of the light reflected and scattered from the ground scene. Apart from Earth radiance, the telescope can be exposed to various light sources by the on-board flight calibration unit (FCU). It features two reflective Spectralon diffusers (one more frequently used than the backup reference) for solar calibration, tunable laser diodes for spectral performance verification, as well as a White Light Source (WLS) for flat field measurements.

In nadir looking mode, the telescope focuses a stripe of the ground scene onto the entrance slit, which is approx. $800 \mathrm{~m}$ wide in ALT and $256 \mathrm{~km}$ in ACT direction, the latter defining the swath width. The slit is composed of an array of rectangular optical multimode fibers, whose principal function is to homogenise the spatially heterogeneous input scene by multiple reflections along the propagation within the fibres. Such devices have been shown to efficiently average out scene contrast and assure a homogeneous output image of the slit [24], which results in highly stable instrument spectral response functions (ISRF). The fibre-based slit, which is also referred to as two-dimensional slit homogeniser (2DSH), is described in further detail in section 3.1.3. After the slit the exiting divergent beam is collimated by a reflective collimator, which is telecentric at the slit interface and shared between the three subsequent spectrometers. Further along the optical path, a cascade of dichroic filters distributes the light to the four individual dispersing elements. The first dichroic reflects the VIS and NIR bands out of the collimated beam, transmitting the SWIR and directing the separated beams to two separate 


\begin{tabular}{|c|c|c|c|}
$\begin{array}{c}\text { Spectral } \\
\text { Band ID }\end{array}$ & $\begin{array}{c}\text { Spectral } \\
\text { Range } \\
(\mathrm{nm})\end{array}$ & $\begin{array}{c}\text { Spectral } \\
\text { Resolution } \Delta \lambda \\
(\mathrm{nm})\end{array}$ & $\begin{array}{c}\text { Spectral Sampling } \\
\text { Ratio }\end{array}$ \\
\hline VIS & $405-490$ & 0.6 & 3 \\
\hline NIR & $747-773$ & 0.12 & 3 \\
\hline SWIR-1 & $1590-1675$ & 0.30 & 3 \\
\hline SWIR-2 & $1990-2095$ & 0.35 & 3 \\
\hline
\end{tabular}
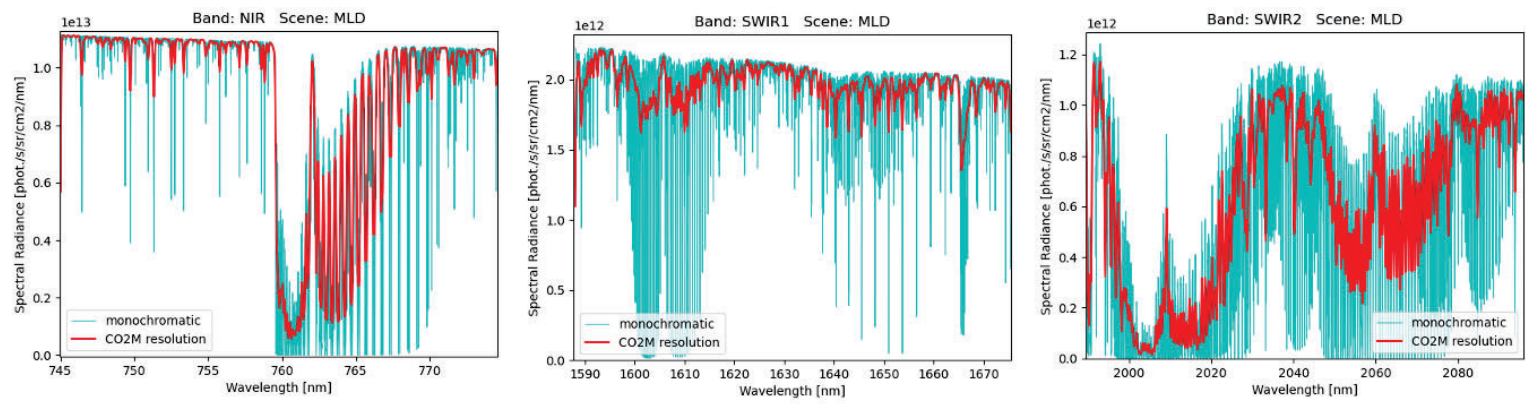

Figure 3. Top: Spectral requirements for measurement of spectra radiance in the thee bands of the carbon dioxide imager (CO2I). Bottom: Simulated TOA spectral radiance in the CO2I bands, monochromatic (light green) and at CO2I spectral resolution (red).

sub-benches for the VIS/NIR, and SWIR optics, respectively (see Fig. 4). The two beams are then spectrally split by subsequent dichroics, and the resulting VIS, NIR, SWIR-1 and SWIR-2 bands are directed towards their respective disperser units. The general layout of the dispersers is identical between the four bands and implements a prism-grating-prism combination $(\mathrm{PG}+\mathrm{P})$ with a transmission grating bonded on the exit surface of the first prism. The dispersive surface is formed by a highly regular binary structure of grooves and trenches filled by a high refractive index material, and will be described in further detail in section 3.1.4. The second prism following the grating after an air-gap is tilted and sized as to minimise the smile distortion. The PG+P devices are all operated in first diffraction order and feature different grating parameters and prism geometries for each band, adapted to the spectral bandwidth and resolution requirements. The two SWIR imagers with f-numbers focus the dispersed slit image onto the detector arrays with de-magnification in both spectral and spatial direction. They are quasi-identical for the two SWIR bands and consist of two aspherical silicon lenses, which are polished to very low surface roughness for straylight reduction. The three-lens NIR imager is based on low index glasses to intrinsically reduce straylight. In the two SWIR bands, a spectral filter is placed between the imagers and the detectors to reduce out-of-band straylight and reject thermal background radiation from the spectrometer optics emitted at its operational temperature of $240 \mathrm{~K}$. The pupil size offered by the telescope is adapted to the SNR requirements, such that the VIS and NIR spectrometer implement a reduced entrance pupil defined at the grating, leading to a very compact arrangement of the combined CO2I and NO2I payloads. The radiance spectra are acquired by silicon CMOS detectors in the VIS and NIR bands (operated at 250K), and by Mercury-Cadmium-Telluride (MCT) focal plane arrays (operated at 150K) in the SWIR spectrometers. They are described in further detail in Section 3.1.5. The Front-End-Electronics (FEE) units for each detector transmit the data to the video acquisition and data processing unit, which performs the spatial binning and transmits the data to the platform data handling system.

In the following subsections we will describe in further detail the most critical components of the CO2I and NO2I payloads. 


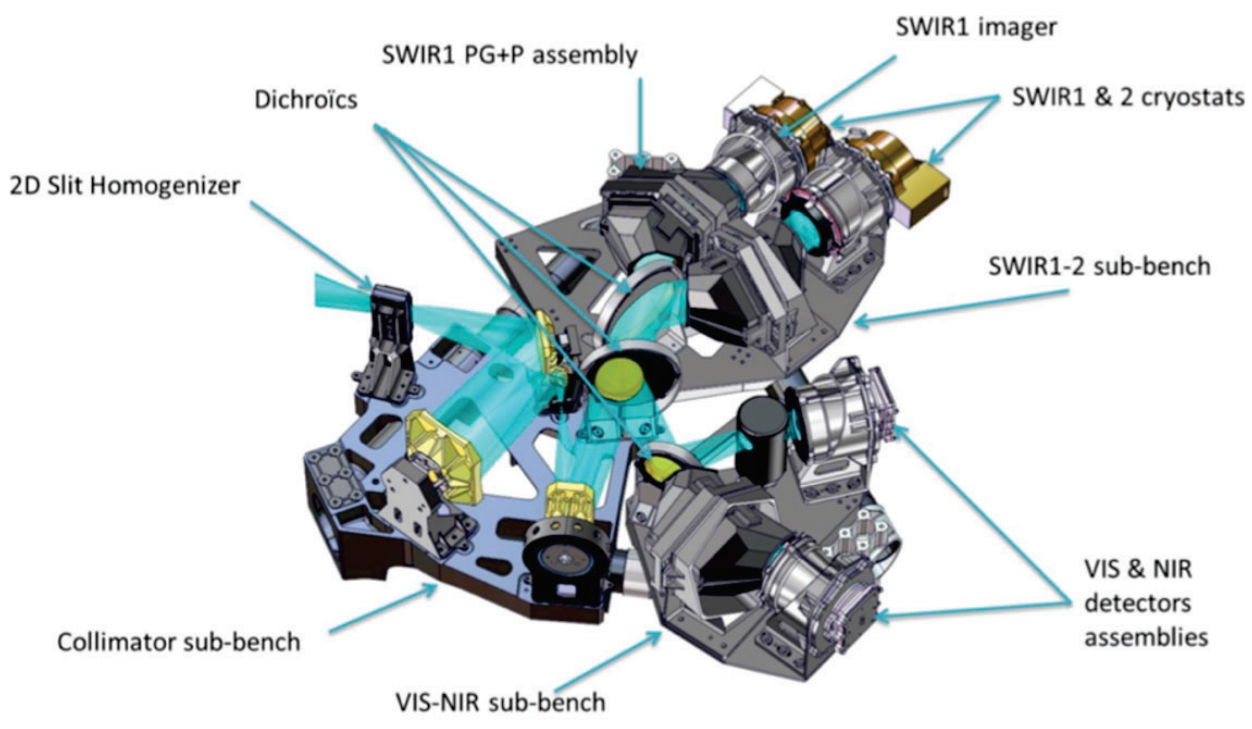

Figure 4. Optical design of the combined CO2I and NO2I instruments (image courtesy of Thales Alenia Space France).

\subsubsection{Fibre-based entrance slit}

CO2M will be the first Earth observation mission deploying a novel kind of entrance slit in its imaging spectrometers, which is based on optical multi-mode fibres [24]. The rationale of this technology is to perform a piece-wise homogenisation of the input scene in both, the spectral and spatial direction, in order to obtain a stable, scene-independent Instrument Spectral Response Function (ILRS). The principle of operation is indicated in the left panel of Fig. 5. The slit is composed of an array of 120 rectangular fibres stacked along the telescope field-of-view in the ACT direction. Each individual fibre core (dimensions: 319um x $121 \mu \mathrm{m}$ ) represents a sub-slit, whose short side defines the slit width and the long side the instantaneous field-of-view of an ACT spatial sample. The light collected over this sample undergoes multiple reflections as it propagates along the fibre length of $20 \mathrm{~mm}$, which averages out the scene contrast to yield a spatially homogeneous near-field image at the fibre exit surface. The homogenisation is achieved in both, the spectral (ALT) and spatial (ACT direction), the latter piece-wise across every ACT spatial sample on ground. This feature distinguishes the fibre-based entrance slit from the slit homogeniser implemented in the Sentinel-5 mission [25], which homogenises only in spectral direction. The homogenisation in 2 dimensions results in a stable, scene-independent slit image on the focal plane, eliminating ISRF distortions from scene heterogeneity in both, spectral and spatial direction [26]. As a consequence, the optical design becomes intrinsically insensitive to the impacts of keystone and smile distortion, allowing for minimisation of optical elements and optimisation of straylight performance.

Another advantage of CO2M's two-dimensional slit homogeniser (2DSH) is that it facilitates a binning strategy resulting in near-perfect spatial co-registration: The separation of the fibre-cores due to the cladding around them results in a stripe-pattern of reduced illumination on the focal plane, as the spectrally dispersed slit image is projected onto the detector array (see right panel of Fig. 5). The detector pixels between these "grey stripes" can be clearly associated to the sub-slits defined by the individual fibres. For each spectral channel a spatial binning scheme is defined such as to piece-wise co-add exclusively the signal generated by light traversing the same fibre. As the spectrally dispersed image of the cladding gaps reflects the keystone distortion of the spectrometer, the binning intervals can be adapted to the as-built frown of the spectrometers, and even adapted in flight. The binning pattern therefore preserves the spatial co-registration within a spectral band and between the four spectrometers sharing the same entrance slit, independent of optical distortion and mechanical mis-alignments (e.g. of the detector position).

The technical implementation of the fibre slit of 2DSH, shown in Fig. 6, is developed by TAS Switzerland 


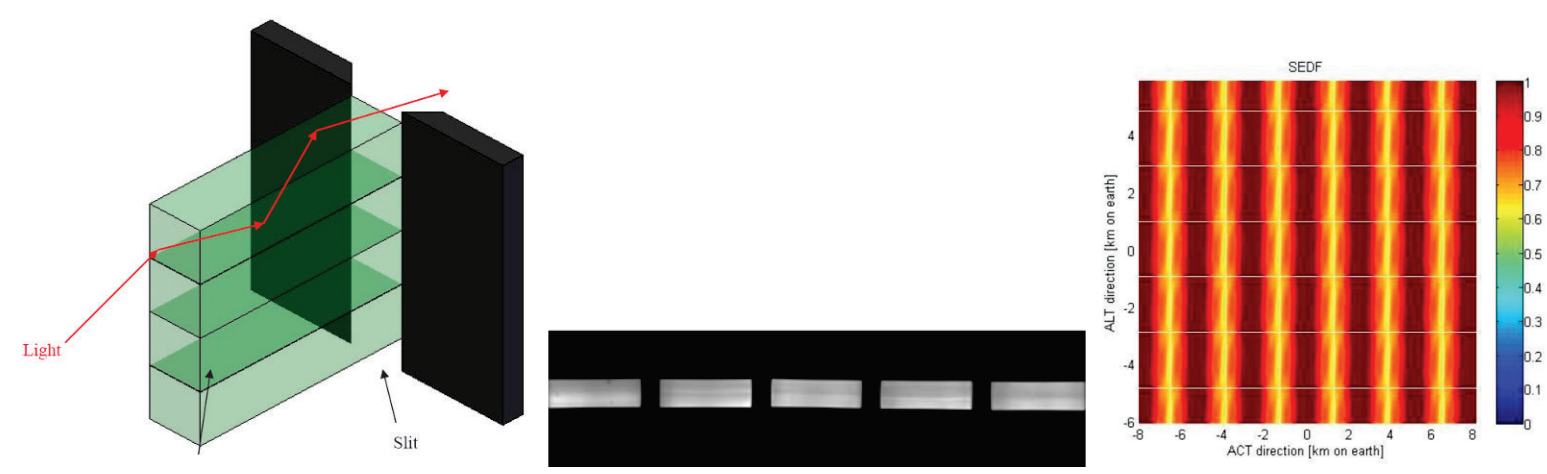

Figure 5. Left: Principle of a fibre-based slit homogeniser, also referred to as two-dimensional slit homogeniser (2DSH). Multiple reflections in the fibre scramble homogenise spatial scene contrast. Middle: Microscope image of a fibre-stack section with gaps between the cores due to cladding. Right: Simulated System Energy Distribution Function (SEDF) describing the spatial performance of the CO2I instrument. The "grey stripes" resulting from the cladding gaps of the fibre-slit are visible as yellow stripes between the ACT spatial samples (images courtesy of IUP, Thales Alenia Space Switzerland, and Optec).
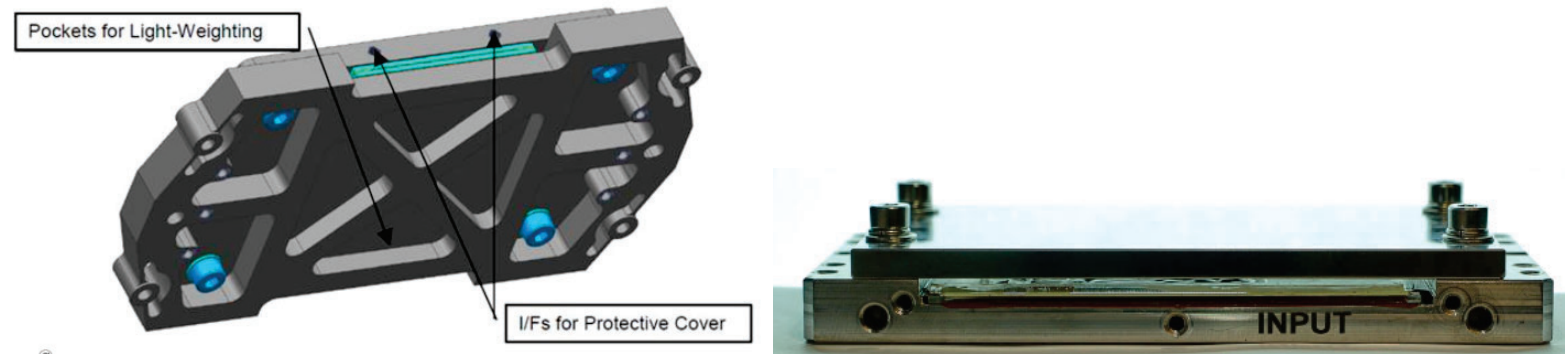

Figure 6. Left: Design sketch (left) and photo of the manufactured prototype of the fibre-based slit for the CO2I and NO2I instruments (courtesy of Thales Alenia Space Switzerland).

(TASiCH) and manufactured by Optec (Italy). The slit is assembled by placing the rectangular fibred one-byone by micro-positioning tools and under microscope supervision, before gluing each fibre to the growing stack of fibres. The prototype device has been subject to a comprehensive quality assessment, in which alignment accuracy, Focal Ratio Degradation (FRD) and transmission performance were measured, and an environmental test campaign has been successfully completed. Straylight and homogenisation performance measurements (both in near- and farfield) are currently in progress. The device will also undergo end-to-end performance testing in a representative spectrometer built in the frame of the "Elegant Breadboard" (EBB) activity for de-risking critical technology.

\subsubsection{Diffraction gratings}

The dispersing elements for all four spectral bands are composed of a prism-grating-prism combination (also grism-prism), with an air-gap between the two prisms as depicted in Fig. 7. This kind of disperser has been developed during the pre-development activities of the CarbonSat candidate mission by Fraunhofer Institute for Applied Optics and Precision Engineering (IOF) in Jena, Germany [27].

The transmissive diffraction grating is formed by sub-wavelength structures etched onto a fused silica substrate, that is bonded onto the exit surface of the first (entrance) prism and operates in 1st diffraction order and Littrow configuration. A schematic sketch, as well as an electron-microscope image of the surface structure is depicted in Fig. 8. The binary pattern of trenches is manufactured by electron-beam lithography and reactive ion-etching, resulting in highly regular structures with excellent diffraction, polarisation and straylight performance. The depth of the trenches is typically on the order of 1-2 $\mu \mathrm{m}$, and the grating period well below the 


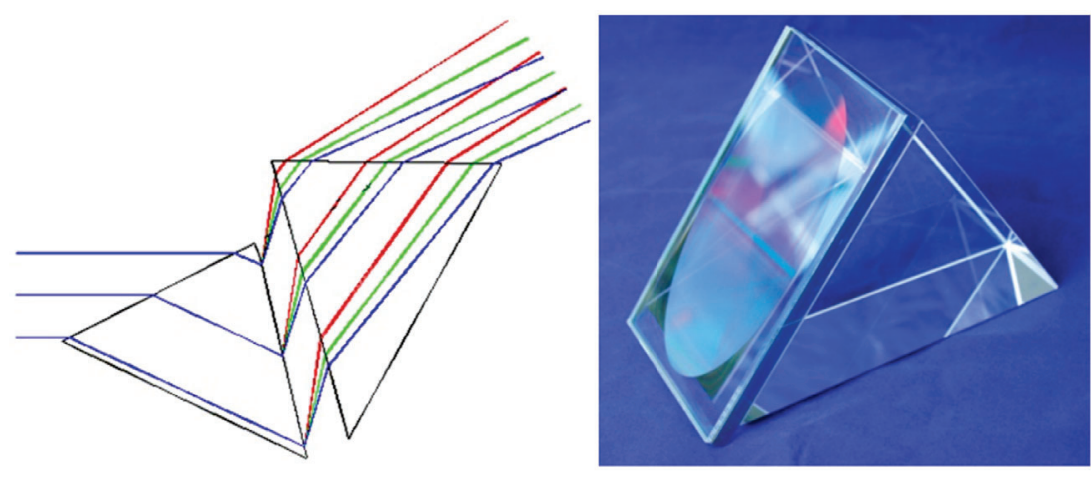

Figure 7. Design sketch of the OPG-P disperser (left) and photo of the grism after bonding of the gratings substrate. The grating can be seen as an oval-shaped structure on the exit surface (photo courtesy of IOF).
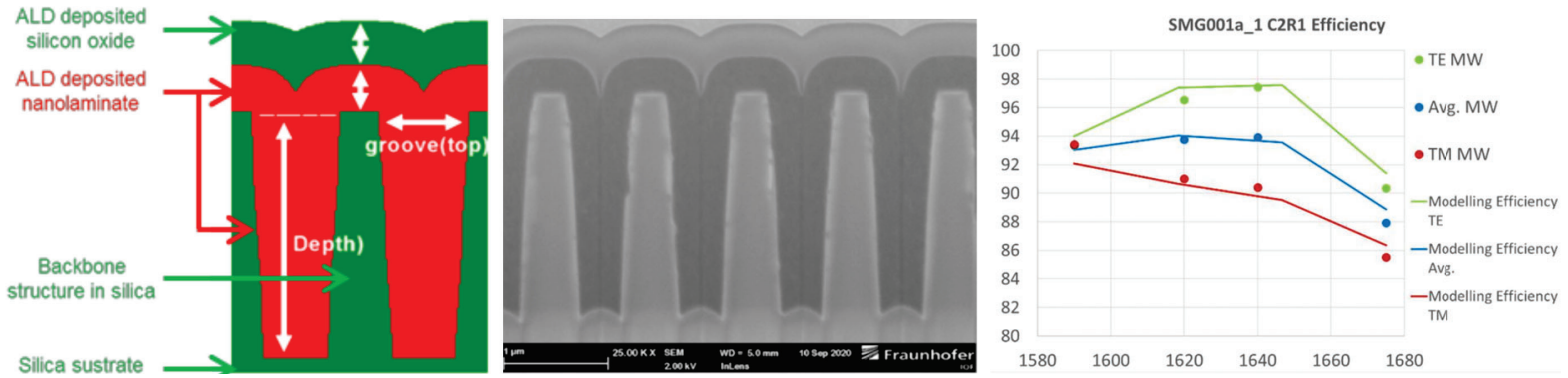

Figure 8. Left: Binary Structure of trenches designed (left) and manufactured (right) on the grating substrate bonded to the prism of the PG-P dispersers. The trenches are filled by a nano-laminate multi-layer coating for adjustment of the refractive index, and sealed by an over-coating of ALD deposited SiO2. Right: Predicted and measured diffraction efficiency of the diffraction grating for the SWIR-1 spectral band. The average efficiency exceeds $90 \%$ over the spectral range and the polarisation sensitivity given by the difference of the TE and TM efficiencies is below $10 \%$ (images courtesy of IOF).

wavelength (between 420nm for the VIS and 1200nm for the SWIR-2 band). The refractive index can be adjusted via a nano-laminate multi-layer coating consisting of alternating stack of $\mathrm{TiO}_{2}$ and $\mathrm{Al}_{2} \mathrm{O}_{3}$ layers, deposited by the atomic layer deposition (ALD) technique. While this coating was limited to the surface of the structure in CarbonSat pre-developments, the technique was further developed for CO2M to fill the entire trench. It is subsequently sealed by ALD deposited silicon oxide to hermetically enclose the binary structure and coating. This grating technology was proven to yield very high diffraction efficiencies above $90 \%$, and polarisation sensitivities well below $10 \%$ (see Fig. 8), as well as low wave-front error. These characteristics enable a compact optical design for high SNR, as well as a low impact on straylight performance, as required by the mission's demanding radiometric accuracy requirements.

\subsubsection{CO2I/NO2I detectors}

Two different types of detectors are used to acquire the 2-dimensional (spatial-spectral) images of the combined CO2I and NO2I instruments. The visible and near infrared channels are equipped by silicon CMOS detectors, while in the short-wave infrared Mercury-Cadmium-Telluride (MCT) technology will be deployed. The CIS120 detector from Teledyne-E2V, which will be used for the VIS and NIR bands, is a relatively new device offering a large format (2048 x 2048 pixels) with small pixel pitch $(10 \mu \mathrm{m})$. This enables an optical image sizing with oversampling in both dimensions, which is beneficial for spectral and radiometric performance. The main characteristics are listed in Fig. 9. For the CO2M mission the latest backside illuminated version of the CIS-120 with enhanced full well capacity $\left(80 \mathrm{ke}^{-}\right)$will be used. The selected device for the SWIR focal plane is the so-called "Next-Generation-Panchromatic" (NGP) detector developed by Lynred under ESA contract [28]. This 
detector is considered to feature high maturity, as it is also baselined for the upcoming missions Sentinel-5 [29] and MicroCarb [17]. Its 1024 x 1024 pixel array with $15 \mu \mathrm{m}$ pitch is sensitive up to 2.5um and offers a charge handling capacity of 680 ke-, which is well-suited for the CO2I and NO2I dynamic ranges. Fig. 10 depicts the NGP and the corresponding detector package.

Comprehensive test and qualification programmes have been initiated for both detectors with a special emphasis on radiometric offset performance, which is particularly critical for the measurement of $\mathrm{XCO}_{2}$. It is expected that these baseline solutions will be confirmed and peformances be consolidated by end of 2021 .

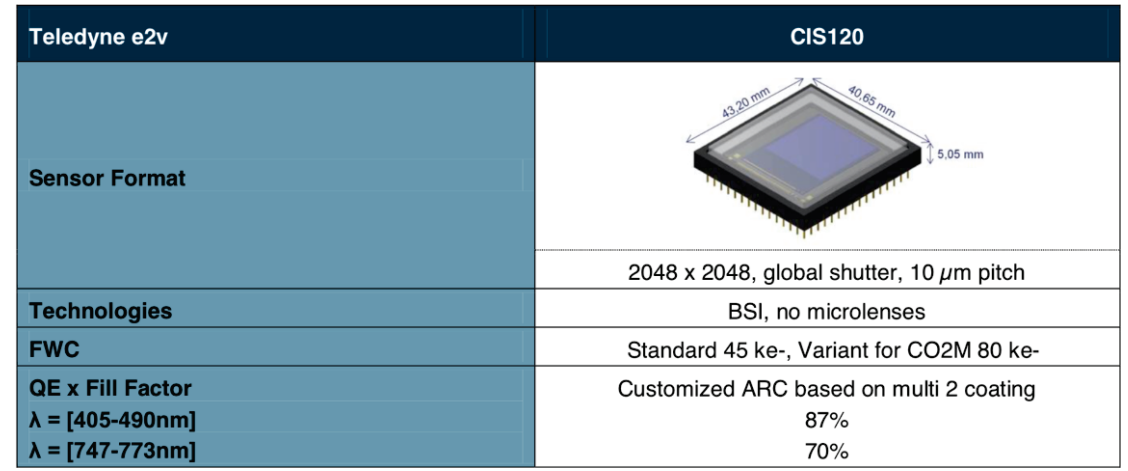

Figure 9. Main characteristics of the CIS-120 silicon CMOS detector from Teledyne-e2v.
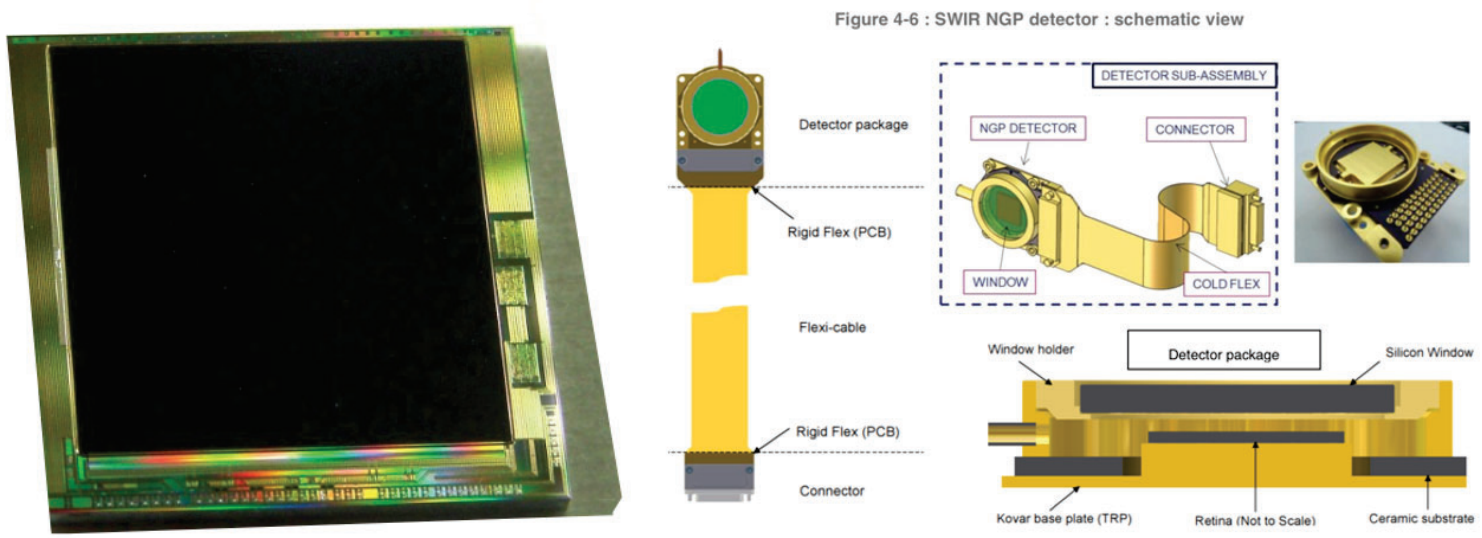

Figure 10. Left: Image of the NGP retina. Right: Design sketch of the proposed detector package.

\subsection{The Multi-Angle Polarimeter}

One of the challenges of measuring carbon dioxide concentration from space is the presence of aerosols in the atmosphere above the ground-scene. Particles of dust, soot and droplets give rise to scattering processes, which modulate the effective path of the light through the atmosphere. As explained in Sec. 3.1.1 the observed spectrum is determined by both, the $\mathrm{CO}_{2}$ concentration and the effective light path. Large amounts of aerosol above the scene modify the light path and hence the depth of the $\mathrm{CO}_{2}$ absorption bands in a way that is indistinguishable from the effect of enhanced gas concentration. For this reason heritage missions like OCO-2 rely on bias correction (using ground-based measurements) and data filtering rejecting measurements with high aerosol optical depth (AOD). However, densely populated areas with large anthropogenic emissions, e.g. in India and China often feature high aerosol loads with optical depth above about 0.3 (see Fig. 11). These regions would be lost to systematic measurement, unless the light path modulation from aerosol can be corrected for. 
In order to facilitate such a correction, aerosol properties above the observed scene (total amount and microphysical parameters) have to be known. The purpose of the Multi-Angle Polarimeter (MAP) is to provide this information, thereby ensuring the required accuracy of the $\mathrm{XCO}_{2}$ retrieval.
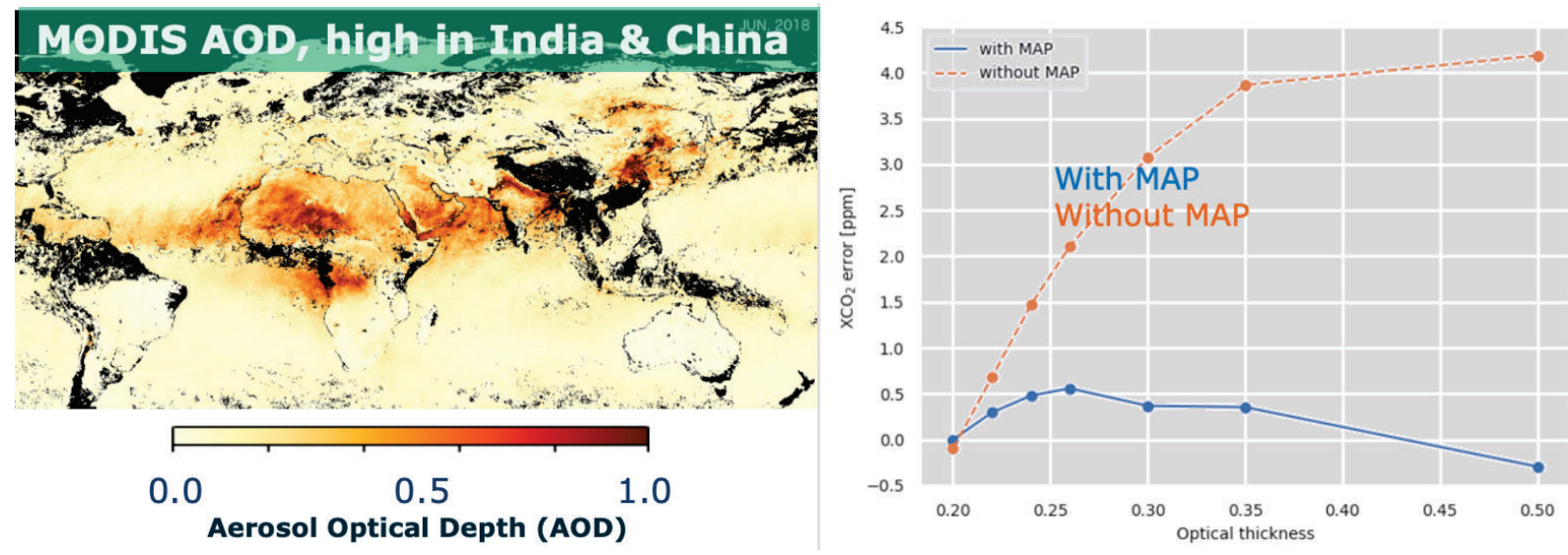

Figure 11. Left: Global map of AOD values as measured by the MODIS instrument, indicating regions with high aerosol loads. Industrial aerosol can be seen over China and India, as well as desert dust in the Sahara and soot from biomass burning in central Africa. These areas are strongly affected by light path modulation from aerosol scattering, and need to be corrected by col-located measurement of the MAP instrument. Right: Simulated $\mathrm{XCO}_{2}$ retrieval accuracy as a function of aerosol optical depth. Introduction of MAP measurements of aerosol parameters strongly improves the accuracy and enables measurement of greenhouse gases over polluted areas (courtesy of SRON).

Heritage missions for space-borne polarimetric measurements are the POLDER instruments on CNES' ADEOS satellites [30], and the SPEXone polarimeter on-board the upcoming PACE mission [31]. Although the aforementioned instruments differ w.r.t. their measurement concept, the common observation principle is to measure radiance and degree of linear polarisation (DoLP) for various viewing angles and spectral bands. The MAP instrument concept for the CO2M mission has been developer by Thales-Alenia Space-UK, and resembles the POLDER instruments in that it measures radiance through various spectral filters and polarisers, transmitting three different angles of polarisation (AOP). However, the novel optical concept is based on large-area focal plane arrays combined with pixel-scale micro-polariser technology. Fig. 12 gives a schematic overview of the measurement principle. The instrument is composed of four identical cameras featuring small reflective telescopes. Their overlapping fields-of-views are sampled under 43 individual viewing angles, spanning a range of $+/-60^{\circ}$ in OZA, both in the forward and backward directions w.r.t. the spacecraft trajectory. The viewing angles are defined by a sequence of spectral filters arranged as stripes along the ACT direction. The colour filter stripes are arranged in sequences of seven wavelength windows (see Table 13) which are combined to define one viewing direction of the push-broom imager. Located underneath the filter substrate is a layer of micro-polarisers, whose grid polariser windows have the same size as the detector pixels. The micro-polariser array, sandwiched between the filter layer and the focal plane, is precisely aligned w.r.t. the underlying detector to provide each pixel with an individual window transmitting a given polarisation angle. Each detector-pixel line in the ACT direction measures the same AOP, which alternates between $0^{\circ}, 60^{\circ}$, and $120^{\circ}$ from line to line. From radiance measurements in three polarisation angles, the DoLP of the light in the transmitted spectral band can be derived. Two repeats of these polariser triplets are combined for better signal-to-noise ratio and spatial sampling performance. The inlay of Fig. 12 depicts a cross-section through the focal plane assembly with the micro-polariser array sandwiched between the detector and the colour stripe filter. In each instant of time, every detector pixel measures a unique combination of polarisation, spectral channel and viewing angle, and the temporal sampling during the forward motion provides the spatial sampling in ALT direction. The detector is operated at high read-out frequency, resulting in dense native sampling (approx. 200m). After on-board binning for data-rate reduction the MAP instrument delivers co-located polarised spectral radiance across the angular range at a $1 \mathrm{~km} \times 1 \mathrm{~km}$ spatial sampling. This data set is then further re-sampled on ground onto the grid defined by the CO2I/NO2I 


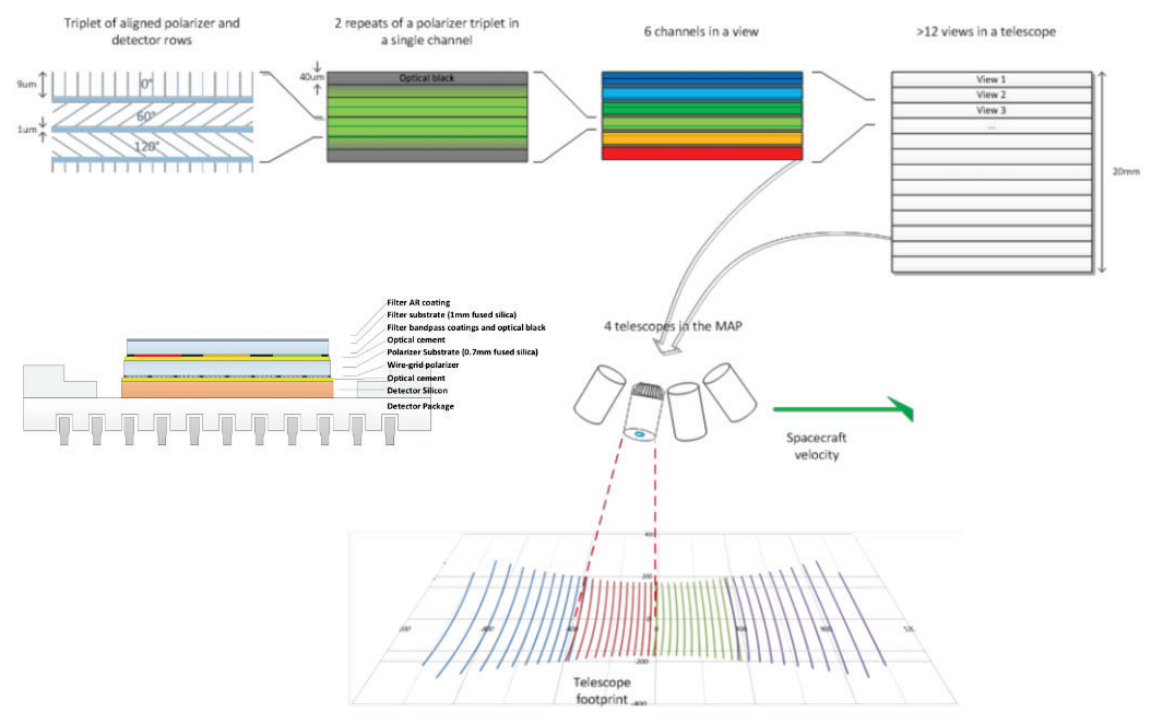

Figure 12. Illustration of the observation concept of the Multi-Angle Polarimeter (MAP) implemented for CO2M. The instrument is comprised of four identical cameras with 12 fields-of-views each, defined by the detector pixels imaged onto the ground scene in different directions. In each viewing direction spectral radiance is measured in six wavelength windows and three polarisations angles, as the light passes through a colour stripe filter and micro-polariser array aligned with the detector pixels. The inlay on the left shows a cross-section through the focal plane assembly, with the micro-polariser array sandwiched between the detector and the colour stripe filter (image courtesy of Thales Alenia Space UK).

\begin{tabular}{|c|c|c|c|}
\hline$*$ & $\begin{array}{c}\text { Channel centre } \\
\text { Wavelength }(\mathrm{nm})\end{array}$ & $\begin{array}{c}\text { Channel } \\
\text { Spectral Width } \\
(\mathrm{nm})\end{array}$ & DoLP \\
\hline MAP-1 & 410 & 20 & Y \\
\hline MAP-2 & 443 & 20 & Y \\
\hline MAP-3 & 490 & 20 & Y \\
\hline MAP-4 & 555 & 20 & Y \\
\hline MAP-5 & 670 & 20 & Y \\
\hline MAP-6 & 753 & 9 & N \\
\hline MAP-7 & 865 & 40 & Y \\
\hline
\end{tabular}

Figure 13. Requirements for the MAP spectral spectral bands.

measurements. The strong impact of the MAP instrument is shown in the right panel of Fig. 11, where the error in simulated $\mathrm{XCO}_{2}$ retrieval is plotted against AOD. The simulation indicates that light path correction from MAP data increases the precision for a wide range of AOD values, and ultimately enables the greenhouse gas measurements over strongly polluted areas.

\subsection{The Could Imager}

The instrument suite of CO2M is complemented and completed by a high-resolution cloud imager (CLIM). The necessity of a CLIM instrument arises from the criticality of cloud contamination within a spatial sample of the CO2I/NO2I instrument. If a spatial sample is partially covered by clouds, complex scattering processes will invalidate the light path estimation from the NIR band and the MAP instrument. While completely overcast ground samples are relatively easily detected and filtered out, small cloud fraction in the range of 1-5\% within the $4 \mathrm{~km}^{2}$ are difficult to identify, and sufficiently modulate the light path to dominate the error of a single-sounding measurement. Experience from heritage missions like OCO-2 have shown that even condensation trails from aircraft within a spatial sample can invalidate the for $\mathrm{XCO}_{2}$ retrieval results. Thin, sub-visible cirrus clouds 
represent a particular challenge as they strongly modulate the light path due the large scattering heights, while being virtually undetectable at visible wavelength. For this reason, the CO2M payload requires spatially coregistered cloud cover measurements over the scene observed by the CO2I/NO2I at sub-sample resolution $(<$ $200 \mathrm{~m})$.
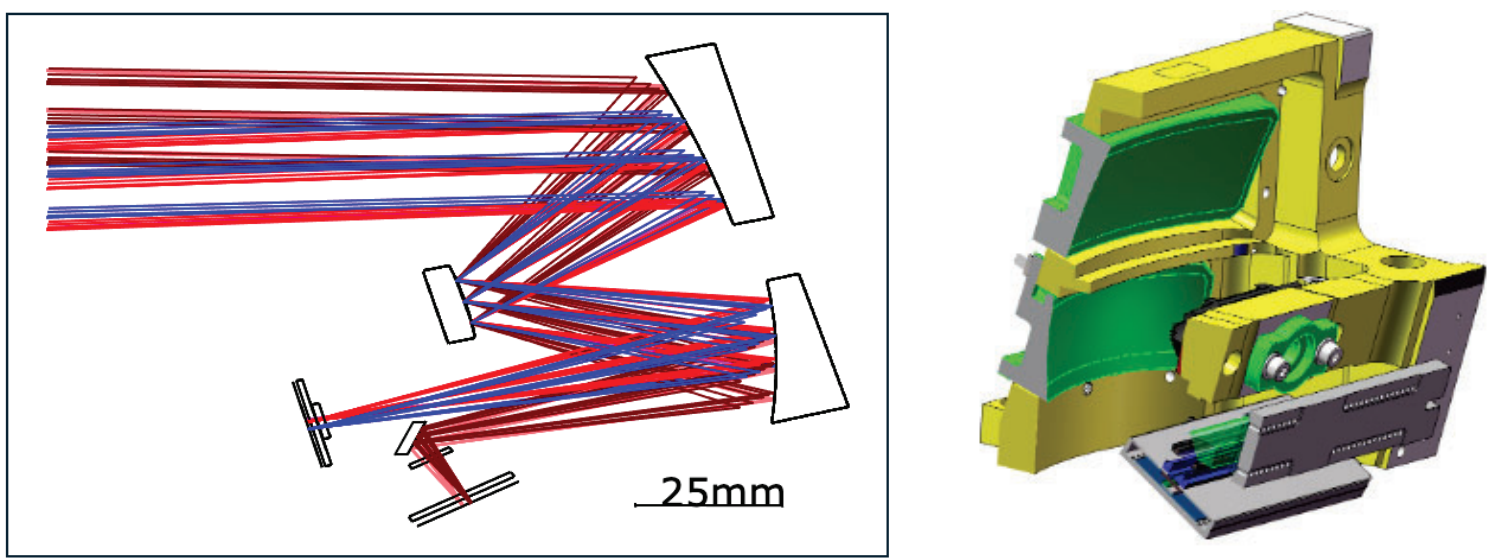

Figure 14. Left: Optical layout of the CLIM instrument. The three spectral bands (VIS, NIR an SWIR) are imaged on two focal planes comprised of linear array detectors. Right: Front and backside view of the CLIM instrument design (image courtesy of OIP).

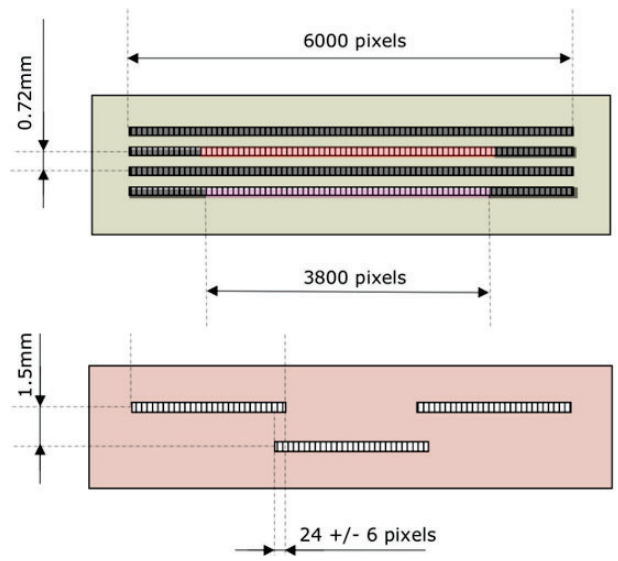

Figure 15. Arrangement of detector lines in the two focal planes. Top: Two of the four lines of a Si CCD detector are used for VIS (2nd line from above) and NIR (lowest line). Bottom: The SWIR focal plane is sampled by three slightly overlapping InGaAs detector lines (image courtesy of OIP).

The requirements derived for these measurements specify radiance measurements in three spectral bands covering the VIS, NIR and SWIR range (centred at $670 \mathrm{~nm}, 753 \mathrm{~nm}$, and $1370 \mathrm{~nm}$, respectively). The SWIR channel is located within a saturated water vapour absorption band, and is primarily important for detection of cirrus clouds. The instrument concept, illustrated in Fig. 14, is based on heritage from the Proba-V mission [32], and is currently being adapted to the specifics of the CO2M mission by the instrument sub-prime OIP Sensor Systems, Belgium. It consists of a reflective TMA telescope spanning a wide swath width of $470 \mathrm{~km}$, transmitting the light through spectral band filters, and imaging the scene on two focal planes, sampled by linear array detectors. The instantaneous field-of-views of the three spectral bands are separated in the ALT direction. Like the other payload instruments, the cloud imager operates in push-broom mode, and spatial co-registration 
between the spectral bands is ensured by timing the detector readout in accordance to the distance of their on-ground projection.

The VIS/NIR focal plane assembly is built around a silicon CCD detector (manufactured by Teledyne/e2v) with four linear arrays, of which only two are used (one each for VIS and NIR), illuminating 3800 out of 6000 pixels $(13 \mu \mathrm{m}$ pitch). This arrangement is illustrated in Fig. 15, along with the setup for the SWIR focal plane array. The dual band filter with the two coatings for NIR and VIS is directly mounted onto the VIS/NIR detector package. In contrast, the SWIR spectral band filter is placed behind a folding mirror at a distance to the focal plane assembly. The latter is based on a Xenics InGaAs detector featuring three lines of 1024 pixels (25um pitch), which are slightly overlapping in the ACT direction to enable radiometric inter-calibration. The absolute radiometric accuracy of the instrument is achieved via Moon calibration and vicariously over known ground targets. The native spatial sampling exceeds the required resolution significantly ( $<90 \mathrm{~m}$ in VIS/NIR), and is available on ground as the data are transmitted without binning. The right panel in Fig. 14 depicts the overall instrument design, and the performance characteristics are listed in Tab. 16.

\begin{tabular}{|l|l|l|l|}
\hline Parameter & CLIM-1 & CLIM-2 & CLIM-3 \\
\hline Number of filuminated native pixels & 5200 & 5200 & 3144 \\
\hline Across track FOV & $34.6^{\circ}$ & $34.6^{\circ}$ & $35^{\circ}$ \\
\hline Swath & $465 \mathrm{~km}$ & $465 \mathrm{~km}$ & $470 \mathrm{~km}$ \\
\hline Spatial Sampling Distance & $174 \mathrm{~m}$ & $174 \mathrm{~m}$ & $340 \mathrm{~m}$ \\
\hline Native SSD (ALTxACT) & $87 \mathrm{mx87m}$ & $87 \mathrm{mx87m}$ & $174 \mathrm{~m} \times 163 \mathrm{~m}$ \\
\hline System Integrated Energy & $\geq 0.6$ & $\geq 0.6$ & $\geq 0.6$ \\
\hline Central Wavelength & $\mathbf{6 7 0 n m}$ & $\mathbf{7 5 3 n m}$ & $\mathbf{1 3 7 0 n m}$ \\
\hline FWHM & $20 \mathrm{~nm}$ & $9 \mathrm{~nm}$ & $\mathbf{1 5 n m}$ \\
\hline
\end{tabular}

Figure 16. Targeted performance parameters of the CLIM.

\section{SUMMARY AND CONCLUSIONS}

In this paper we have presented the instrument suite of the Copernicus CO2M mission, highlighting the individual objectives, concepts and technical challenges of the payload components. The accommodation of the complete payload is depicted in Fig. 17. The payload design capitalises on lessons learned and experience from heritage missions, and addresses driving requirements by a number of novel techniques, which have been developed and matured by previous ESA-funded instrument studies. Design and operation of the four instruments is fully complementary and optimised to maximise single-sounding precision and accuracy of column-averaged carbon dioxide concentration, as required to quantify anthropogenic sources, like power plants and large cities. They are operated in an orchestrated way and their data are used synergistically for the retrieval of greenhouse gas concentrations. The push-broom imager for carbon dioxide and methane is composed of three spectrometers with common entrance slit and collimator, and will provide continuous and detailed global mapping of greenhouse gas concentration. It is combined with a fourth spectrometer measuring nitrogen dioxide column amounts over the scene, which serves as a tracer for weaker point sources and identification of the emission plume shape. An example of the expected image quality of the CO2I/NO2I over major European $\mathrm{CO}_{2}$ emission sources is shown in Fig. 1. The simulation demonstrates the ability to resolve individual point sources as well as the emission plume intensity and shape. The Multi-Angle Polarimeter (MAP) simultaneously measures aerosol parameters required for light path correction, and thereby enabling accurate retrievals even over highly polluted industrial regions. Finally, the high-resolution cloud imager (CLIM) detects clouds at sub-sample resolution for advanced data screening and filtering of cloud-contaminated samples.

After its targeted launch in 2025, the observing system of the intended satellite constellation will deliver global maps of greenhouse gas concentration with high spatial resolution and precision at unprecedented spatial 
coverage. This unique data set will enable reliable monitoring of anthropogenic greenhouse gas emissions, providing actionable information for policy makers, and supporting governments and communities to evaluate their crucial efforts in reducing greenhouse gas emissions for the protection of our planet's climate [33].

1) $\mathrm{Si}_{3}$ 4 ceramic structure
2) Thermal guard
3) Telescope
4) Flight Calibration Unit
5) Instrument Support Panel
6) Dissipative electronics
7) Ultra Stable Interface Bench
8) MAP
9) CLIM
10) Star trackers
11) Cryogenic passive radiator
12) External housing panels
overlayed with MLI



Figure 17. Overview of the complete system including all instruments and platform (courtesy of TAS France).

\section{ACKNOWLEDGEMENTS}

The authors are grateful to the industrial consortia participating in the CO2M industrial studies, in particular the consortium led by OHB System. Germany, and the instrument prime Thales Alenia Space in France. We also would like to thank the CO2M Mission Advisory Group for the collaborative efforts in developing the requirements for this mission.

\section{REFERENCES}

[1] Paris Agreement to the United Nations Framework Convention on Climate Change, Dec. 12, 2015, T.I.A.S. No. 16-1104 (2015)

[2] Janssens-Maenhout, G., Pinty, B., Dowell, M., Zunker, H., Andersson, E., Balsamo, G., Bezy, J., Brunhes, T., Bosch, H., Boikov, B., Brunner, D., Buchwitz, M., Crisp, D., Ciais, P., Counet, P., Dee, D., Denier Van Der Gon, H., Dolman, H., Drinkwater, M., Dubovik, O., Engelen, R., Fehr, T., Fernandez, V., Heimann, M., Holmlund, K., Houweling, S., Husband, R., Juvyns, O., Kentarchos, A., Landgraf, J., Lang, R., Löscher, A., Marshall, J., Meijer, Y., Nakajima, M., Palmer, P.I., Peylin, P., Rayner, P., Scholze, M., Sierk, B., Tamminen, J. and Veefkind, P.,: Towards an operational anthropogenic CO2 emissions monitoring and verification support capacity, Bulletin of the American Meteorological Society, ISSN 0003-0007 (online), 101 (8), 2020, p. E1439-E1451, JRC119796 (2020)

[3] Pinty, B., Ciais, P., Dee, D., Dolman, A., Dowell, M., Engelen, R., Holmlund, K., Janssens-Maenhout, G., Meijer, Y., Palmer, P., Scholze, M., Denier Van Der Gon, H., Heimann, M., Juvyns, O., Kentarchos, A. and Zunker, H., CO2: An operational anthropogenic CO2 emissions monitoring and verification support capacity, EUR 29817 EN, Publications Office of the European Union, Luxembourg, 2019, ISBN 978-92-7609004-5 (online), doi:10.2760/182790 (online), JRC117323, (2019)

[4] Buchwitz, M., R. de Beek, J. P. Burrows, H. Bovensmann, T. Warneke, J. Notholt, J. F. Meirink, A. P. H. Goede, P. Bergamaschi, S. Körner, M. Heimann, and A. Schulz, Atmospheric methane and carbon dioxide 
from SCIAMACHY satellite data: Initial comparison with chemistry and transport models, Atmos. Chem. Phys., 5, 941-962, 2005

[5] Crisp, D., et al., The Orbiting Carbon Observatory (OCO) mission, Adv. Space Res., 34, 700-709, 2004

[6] Kuze, A., Suto, H., Nakajima, M., and Hamazaki, T.: Thermal and near infrared sensor for carbon observation Fourier-transform spectrometer on the Greenhouse Gases Observing Satellite for greenhouse gases monitoring, Applied Optics, 48, 6716-6733, doi:10.1364/AO.48.006716

[7] Crisp, D., Miller, C. E., and DeCola, P. L.: NASA Orbiting Carbon Observatory: measuring the column averaged carbon dioxide mole fraction from space, Journal Of Applied Remote Sensing, 2, 23 508, doi:10.1117/1.2898457, 2008

[8] R. R. Basilio, H. R. Pollock, S. L. Hunyadi-Lay: OCO-2 (Orbiting Carbon Observatory-2) mission operations planning and initial operations experiences, Proceedings Volume 9241, Sensors, Systems, and NextGeneration Satellites XVIII; 924105 (2014) https://doi.org/10.1117/12.2074164

[9] D. Crisp: Measuring atmospheric carbon dioxide from space with the Orbiting Carbon Observatory-2 (OCO2), SPIE Optical Engineering and Applications, San Diego, 2015, Proc. Vol. 9607, Earth Observing Systems XX; 960702 (2015) https://doi.org/10.1117/12.2187291

[10] Nassar, R., Hill, T. G., McLinden, C. A., Wunch, D., Jones, D. B. A., Crisp, D. (2017). Quantifying CO2 emissions from individual power plants from space. Geophysical Research Letters, 44, 10,045-10,053. https://doi.org/10.1002/ 2017GL074702

[11] Y. Liu et al., The Pre-launch Status of TanSat Mission, 12th International Workshop on Greenhouse Gas Measurements from Space (IWGGMS-12)," Kyoto University, Kyoto, Japan, June7- 9, 2016

[12] D.Yang, Y. LIU, H. Boesch, L. Yao, Antonio Di Noia, Z. Cai, N. Lu, D. Lyu, M. Wang, J.Wang, Z. Yin, and Y. Zheng: A New TanSat XCO2 Global Product towards Climate Studies, Advances in Atmospheric Sciences, VOL. 38, 8-11, 2021

[13] Hiroshi Suto, Fumie Kataoka, Nobuhiro Kikuchi, Robert O. Knuteson, Andre Butz, Markus Haun, Henry Buijs, Kei Shiomi, Hiroko Imai, and Akihiko Kuze, Thermal and near-infrared sensor for carbon observation Fourier transform spectrometer-2 (TANSO-FTS-2) on the Greenhouse gases Observing SATellite-2 (GOSAT2) during its first year in orbit, Atmos. Meas. Tech., 14, 2013-2039, 2021 https://doi.org/10.5194/amt-142013-2021

[14] H. Suto, F. Kataoka, N. Kikuchi, R. O. Knuteson, A. Butz, M. Haun, H. Buijs, K. Shiomi, H. Imai, and A. Kuze, Thermal and near-infrared sensor for carbon observation Fourier transform spectrometer-2 (TANSOFTS-2) on the Greenhouse gases Observing SATellite-2 (GOSAT-2) during its first year in orbit, Atmos. Meas. Tech., 14, 2013-2039, 2021 https://doi.org/10.5194/amt-14-2013-2021

[15] A. Eldering, T. E. Taylor, C. W. O'Dell, and R. Pavlick: The OCO-3 mission; measurement objectives and expected performance based on one year of simulated data, Atmos. Meas. Tech. Discuss., https://doi.org/10.5194/amt-2018-357 Manuscript under review for journal Atmos. Meas. Tech.

[16] T. Taylor et al.: OCO-3 early mission operations and initial (vEarly) XCO2 and SIF retrievals, Remote Sensing of Environment, Volume 251, 15 December 2020, 112032, https://doi.org/10.1016/j.rse.2020.112032

[17] Véronique Pascal, Christian Buil, Elodie Cansot, Jacques Loesel, Laurie Tauziede, Clémence Pierangelo, François Bermudo: A new space instrumental concept based on dispersive components for the measurement of CO2 concentration in the atmosphere, Proceedings Volume 10564, International Conference on Space Optics — ICSO 2012; 105641R (2017) https://doi.org/10.1117/12.2309052

[18] Crowell, S. and Moore, B.: The GeoCarb Mission, EGU General Assembly 2020, Online, 4-8 May 2020 , EGU2020-20213, https://doi.org/10.5194/egusphere-egu2020-20213, 2020

[19] Buchwitz, M., Reuter, M., Bovensmann, H., Pillai, D., Heymann, J., Schneising, O., Rozanov, V., Krings, T., Burrows, J. P., Boesch, H., Gerbig, C., Meijer, Y., and Löscher, A., Carbon Monitoring Satellite (CarbonSat): Assessment of atmospheric $\mathrm{CO}_{2}$ and $\mathrm{CH}_{4}$ retrieval errors by error parameterization, Atmos. Meas. Tech., 6, 3477-3500 (2013)

[20] Gerrit Kuhlmann, Grégoire Broquet, Julia Marshall, Valentin Clément, Armin Löscher, Yasjka Meijer, and Dominik Brunner: Detectability of CO2 emission plumes of cities and power plants with the Copernicus Anthropogenic CO2 Monitoring (CO2M) mission, Atmos. Meas. Tech., 12, 6695-6719, 2019 https://doi.org/10.5194/amt-12-6695-2019 
[21] Veefkind, J.P., Aben, I., McMullan, K., Förster, H., de Vries, J., Otter, G., Claas, J., Eskes, H. J., de Haan, J.F., Kleipool, Q., van Weele, M., Hasekamp, O., Hoogeveen, R., Landgraf, J., Snel, R., Tol, P., Ingmann, P., Voors, R., Kruizinga, B., Vink, R., Visser, H., and Levelt, P. F., TROPOMI on the ESA Sentinel-5 Precursor: A GMES mission for global observations of the atmospheric composition for climate, air quality and ozone layer applications, Remote Sensing of Environment, Volume 120, Pages 70-83 (2012)

[22] B. Sierk, J.-L. Bézy, A. Löscher, and Y. Meijer: The European CO2 Monitoring Mission: observing anthropogenic greenhouse gas emissions from space, Proc. SPIE 11180, International Conference on Space Optics — ICSO 2018, 111800M; doi: 10.1117/12.2535941, 2019

[23] Lianghai Wu, Joost aan de Brugh, Yasjka Meijer, Bernd Sierk, Otto Hasekamp, Andre Butz, and Jochen Landgraf: $\mathrm{XCO}_{2}$ observations using satellite measurements with moderate spectral resolution: investigation using GOSAT and OCO-2 measurements, Atmos. Meas. Tech., 13, 713-729, 2020; https://doi.org/10.5194/amt-13-713-2020

[24] Amann, S. Duong-Ederer, Q., Haist, T., Sierk, B., Guldimann. B., Osten, W.: Characterization of fiberbased slit homogenizer devices in the NIR and SWIR, International Conference on Space Optics (ICSO), 2018

[25] T. Hummel, C. Meister, J. Krauser, and M. Wenig: Slit homogenizer introduced performance gain analysis based on Sentinel-5/UVNS spectrometer, manuscript in preparation; https://doi.org/10.5194/amt-2021-15

[26] Caron, J., Sierk, B., Bézy, J.L., Löscher, A., and Meijer, Y., The CarbonSat candidate mission: Radiometric and spectral performances over spatially heterogeneous scenes, Proceedings of the International Conference on Space Optics (ICSO), Tenerife, Spain, 2014

[27] B. Guldimann, A. Deep, R. Vink: Overview on grating developments at ESA, CEAS Space Journal volume 7, pages433-451, 2015

[28] B. Fieque, P. Chorier, A. Lamoure, O. Offranc: Status of space activity and science detectors development at Sofradir, Proceedings Volume 11180, International Conference on Space Optics — ICSO 2018; 111803E (2019) https://doi.org/10.1117/12.2536041

[29] T. Gühne, C. Keim, P. Bartsch, S. Weiß, M. Melf, W. Seefelder: Sentinel-5 instrument: status of design, performance, and development, Proceedings Volume 10423, Sensors, Systems, and Next-Generation Satellites XXI; 1042309 (2017) https://doi.org/10.1117/12.2278564

[30] O. Dubovik et al.: Polarimetric remote sensing of atmospheric aerosols: Instruments, methodologies, results, and perspectives, J. Quant. Spec. Rad. Trans., Volume 224, February 2019, Pages 474-511, https://doi.org/10.1016/j.jqsrt.2018.11.024

[31] A. van Amerongen, J. Rietjens, J. Campo, E. Dogan, J Dingjan, R. Nalla, J. Caron, O. Hasekamp: SPEXone: a compact multi-angle polarimeter, Proc. Vol. 11180, International Conference on Space Optics — ICSO 2018; 111800L (2019) https://doi.org/10.1117/12.2535940

[32] W. Dierckx, S. Sterckx, I. Benhadj, S. Livens, G. Duhoux, T. Van Achteren, M. Francois, K. Mellab, G. Saint (2014) PROBA-V mission for global vegetation monitoring: standard products and image quality, International Journal of Remote Sensing, 35:7, 2589-2614, DOI: 10.1080/01431161.2014.883097

[33] P. Sellers, Cancer and Climate Change, The New York Times, 2016, https://www.nytimes.com/2016/01/17/opinion/sunday/cancer-and-climate-change.html 